Gut and Liver, Vol. 12, No. 4, July 2018, pp. 411-419

\title{
Comparison of Tight Junction Protein-Related Gene mRNA Expression Levels between Male and Female Gastroesophageal Reflux Disease Patients
}

\author{
Jin Joo Kim ${ }^{1,2}$, Nayoung Kim ${ }^{1,3}$, Ji Hyun Park ${ }^{1}$, Young Sun Kim ${ }^{4}$, Sun Min Lee ${ }^{3}$, Dong Ho Lee ${ }^{1,3}$, and Hyun Chae Jung ${ }^{1}$ \\ ${ }^{1}$ Department of Internal Medicine and Liver Research Institute, Seoul National University College of Medicine, Seoul, ${ }^{2}$ Department of Internal \\ Medicine, Gyeongsang National University Changwon Hospital, Changwon, ${ }^{3}$ Department of Internal Medicine, Seoul National University \\ Bundang Hospital, Seongnam, and ${ }^{4}$ Department of Internal Medicine, Healthcare Research Institute, Seoul National University Hospital \\ Healthcare System Gangnam Center, Seoul, Korea
}

See editorial on page 373.

Background/Aims: Male predominance has been observed in the erosive reflux disease (ERD), but reverse finding in nonerosive reflux disease (NERD). This suggests sexspecific medicine approach is needed but its mechanism is remained to be elucidated. We aimed to compare clinical characteristics and mRNA expression levels of tight junctionrelated proteins between male and female gastroesophageal reflux disease (GERD). Methods: Sixteen healthy controls, 45 ERD, and 14 NERD patients received upper endoscopies and completed questionnaires. Quantitative real-time polymerase chain reactions of occludin (OCLN), zonal occludens (ZO) 1, claudin-1 (CLDN1) and claudin-4 (CLDN4), and neurokinin 1 receptor (NK1R) were performed in the distal esophageal mucosal specimen. These results were analyzed by sex. Results: Female GERD patients were affected more by reflux symptoms than males. The impairment of overall quality of life was more prominent in female patients with reflux symptoms than male patients $(5.6 \pm 0.2$ vs $4.9 \pm 0.6$, $p=0.009$ ). The levels of OCLN mRNA expression were significantly lower in the male ERD group. On the other hand, those of CLDN1, CLDN4, and NK1R except ZO-1 were significantly higher in the male ERD group. Conclusions: We demonstrated that female ERD/NERD patients were affected more by GERD and male ERD patients showed significant changes of tight junction protein mRNA expression levels. (Gut Liver 2018;12:411-419)

Key Words: Gastroesophageal reflux; Tight junction proteins; Occluding; Claudin

\section{INTRODUCTION}

Gastroesophageal reflux disease (GERD) is a common disease and categorized into erosive reflux disease (ERD) or nonerosive reflux disease (NERD) according to the endoscopic evaluation. ERD is thought to be able to progress to Barrett's esophagus (BE) and even to esophageal adenocarcinoma (EAC), ${ }^{1-3}$ whereas NERD is not. Notably, male predominance has been observed through ERD spectrum and female predominance has been observed in NERD. ${ }^{4-14}$ These epidemiological data suggest that males are more susceptible to the physical mucosal damages and females have more enhanced pain perception. From these epidemiologic background, sex-specific medicine seem to be promising for providing more appropriate treatment options for both male and female GERD patients. ${ }^{15-17}$

Esophageal epithelium is important for the protection from noxious stimulus of gastric refluxate. Relative impermeability of the esophageal epithelium is a crucial factor for the barrier function and is related to the tight junction proteins. Hence, synthesis or degradation of these tight junction proteins have been regarded as a promising GERD biomarker. So far, in animal and in vitro models of GERD, some changes in the expression and localization of claudin-3 (CLDN3) and claudin-4 (CLDN4) have been shown. ${ }^{18,19}$ Also, in human studies, expressions of claudin-1 (CLDN1), claudin-2 (CLDN2), CLDN4, zonula occludens (ZO)-1, filaggrin, and occludin (OCLN) have been altered in GERD patients. ${ }^{20-22}$ As these tight junction proteins are important structural components for the barrier function in esophageal epithelial cells $\mathrm{s}^{23,24}$ and males are prone to be more susceptible to the mucosal damage than females, it has been assumed the differences in tight junction proteins might contribute to the different clinical characteristics of male and female

Correspondence to: Nayoung Kim

Department of Internal Medicine, Seoul National University Bundang Hospital, 82 Gumi-ro 173beon-gil, Bundang-gu, Seongnam 13620, Korea

Tel: +82-31-787-7008, Fax: +82-31-787-4051, E-mail: nayoungkim49@empas.com

Received on September 20, 2017. Revised on January 6, 2018. Accepted on January 30, 2018. Published online March 21,2018

pISSN 1976-2283 eISSN 2005-1212 https://doi.org/10.5009/gnl17419

@ This is an Open Access article distributed under the terms of the Creative Commons Attribution Non-Commercial License (http://creativecommons.org/licenses/by-nc/4.0) which permits unrestricted non-commercial use, distribution, and reproduction in any medium, provided the original work is properly cited. 
GERD patients.

In concordance with this assumption, recent studies suggested that estrogen have an important role to increase esophageal mucosal resistance by up-regulating the expression of esophageal tight junction protein. ${ }^{25,26}$ For example, Honda et al. ${ }^{25}$ conducted an animal study to identify the role of estrogen treatment on the esophageal epithelial barrier function and demonstrated that $17 \beta$-estradiol administration reduced the dilation of the intercellular space caused by luminal irritants. Moreover, $17 \beta$-estradiol administration increased the expression of OCLN. ${ }^{25}$

From this background, we hypothesized that more fortified esophageal tight junction proteins have a protective effect against the development of ERD in females, and less fortified esophageal barriers make males more vulnerable to the development of ERD. To verify this assumption, we aimed to evaluate the differences of esophageal tight junction protein mRNA expression levels, including OCLN, ZO-1, CLDN1 and CLDN4, between male and female GERD patients and also assessed their relationship with endoscopic and clinical characteristics. In addition, we analyzed if there are any differences in the acidinduced inflammation process between males and females evaluating mRNA expression levels of neurokinin 1 receptor (NK1R), which is one of important inflammatory mediators as an extension of our previous study. ${ }^{27}$

\section{MATERIALS AND METHODS}

\section{Subjects}

Subjects were prospectively enrolled at the Department of Gastroenterology of Seoul National University Bundang Hospital (SNUBH) (outpatient clinic of N.K.) between March 2013 and May 2016. All subjects were of Korean origin and received upper gastrointestinal endoscopies and completed questionnaires about GERD symptoms, including both esophageal and extra-esophageal symptoms, sleep, emotional state and quality of life (QOL) under the supervision of a well-trained interviewer. Esophageal motility disorders were evaluated by esophageal manometry in subjects with symptoms, such as dysphagia, and/or patients with endoscopic findings suspicious of motility disorders. Subjects were excluded if there was a history of gastrointestinal surgery, BE, esophageal motility disorder, duodenal ulcer, benign gastric ulcer or gastroduodenal cancer and any history of systemic disease requiring chronic medication (except for hypertension and diabetes mellitus).

The subjects were classified into three groups; ERD, NERD and control groups. ERD group was defined as the patients with mucosal breaks at gastroesophageal junction in endoscopic findings, according to the LA classification of esophagitis. NERD group was defined as the patients who had more than one episode of heartburn or acid regurgitation per week with normal endoscopic findings, and diagnosed based on proton pump inhibitor (PPI) response without $\mathrm{pH}$ or multi-channel intraluminal impedance study. Positive response for the PPI was defined as an improvement of more than 50\% of symptom frequency after 2-week PPI intake. Subjects with no esophageal reflux symptoms and normal endoscopic findings from health check-up were assigned as the control group.

The Institutional Review Board of SNUBH approved this study (IRB No. B-1211/180-003), and written informed consent was obtained from all participants.

\section{Symptom assessment}

Two questionnaires were used to evaluate GERD symptoms. Seven GERD symptoms which consisted of both esophageal and extra-esophageal symptoms were checked (Supplementary Fig.

1). ${ }^{28-30}$ Esophageal symptoms were heartburn and acid regurgitation, and extra-esophageal symptoms were chest pain, cough, globus sensation, hoarseness, and epigastric soreness. GERD impact scale (GIS) was also used to assess GERD symptoms and impact of these symptoms on everyday life. GIS is a validated questionnaire that was developed from systematic literature review and has been demonstrated to have good psychometric properties in diagnosis and is considered as a useful communication tool in managing GERD. ${ }^{28,31}$ GIS consists of five questions about symptoms and four questions about impact of symptoms on sleep, eating or drinking, job or daily activities and taking medication without prescription. ${ }^{28,31}$ Subjects answered each question by four scales; 3 point for "daily," 2 for "often," 1 for "sometimes" and 0 for "never." The use of text of the GIS was generously permitted from AstraZeneca LP $\left({ }^{\circ} 2001\right)$ (Supplementary Fig. 1). Accordingly, higher score indicates that the subjects suffered more severe GERD symptoms and their daily lives were more impaired by GERD symptoms.

World Health Organization quality of life scale abbreviated version (WHOQOL-BREF) ${ }^{32,33}$ was used to assess the QOL of each subject. It consists of questions about overall QOL and general health, and four domains as the following: physical health, medical treatment, psychological health and environmental domains, including access to health services. Its results are expressed as an overall score (range, 0 to 100) and domain score (range, 0 to 100). In this scale, higher score indicates better QOL.

\section{Upper endoscopy and taking biopsy}

During the upper endoscopic examination, two biopsies were taken gently using standard biopsy forceps at a fixed position $3 \mathrm{~cm}$ above the squamo-columnar junction in order to achieve sample consistency not only from all GERD but also from control subjects. The biopsy was done at the normal-looking mucosa. The extent of mucosal damage of ERD was assessed using the LA grading system.

\section{RNA isolation and reverse transcription}

In order to stabilize and protect RNA from degradation, biopsy specimens were stored in RNAlater Solution (Ambion, Austin, 
TX, USA) at $4^{\circ} \mathrm{C}$ after the endoscopy. Total RNAs were extracted from the esophageal mucosal biopsy specimen using TRIzol ${ }^{\circledR}$ reagent (Invitrogen, Carlsbad, CA, USA) as recommended by the manufacturer and the collected RNA was purified using RNeasy mini kits (Qiagen, Valencia, CA, USA). RNA samples were diluted to a final concentration of $0.5 \mathrm{mg} / \mathrm{mL}$ in RNase-free water and stored at $-80^{\circ} \mathrm{C}$ until the next step. Synthesis of the cDNA was performed with $1 \mu \mathrm{g}$ of total RNA with Moloney murine leukemia virus (M-MLV) reverse transcription reagents (Invitrogen). The reverse-transcription reaction consisted of $4 \mu \mathrm{L}$ of firststrand buffer, $500 \mathrm{mM}$ deoxynucleoside triphosphate mixture, $2.5 \mathrm{mM}$ oligo(dT) 12-18 primer, $0.4 \mathrm{U} / \mathrm{mL}$ ribonuclease inhibitor and $1.25 \mathrm{U} / \mathrm{mL}$ M-MLV reverse transcriptase (Invitrogen). The thermal cycling parameters for the reverse transcription were 10 minutes at $65^{\circ} \mathrm{C}, 50$ minutes at $37^{\circ} \mathrm{C}$, and 15 minutes at $70^{\circ} \mathrm{C}$.

\section{Real-time quantitative polymerase chain reaction}

Real-time quantitative polymerase chain reaction (qPCR) was performed in triplicate by using a StepOnePlus Real-Time PCR (Applied Biosystems, Foster City, CA, USA) with SYBR Premix Ex TaqTM (Takara Bio, Shiga, Japan) according to manufacturers' instructions and protocols. The following primers were used: OCLN forward, TGT GGA TCC CCA GGA GGC CA; OCLN reverse, AGG CAC GTC CTG TGT GCC TG; CLDN1 forward, GGG CTG CAG CTG TTG GGC TT; CLDN1 reverse, GGG TTG CTT GCA ATG TGC TGC T; CLDN4 forward, CCC CGA GAG AGA GTG CCC TG; CLDN4 reverse, AGC GTC CAC GGG AGT TGA GGA; ZO-1 forward, CAA GAT AGT TTG GCA GCA AGA GAT G;
Z0-1 reverse, ATC AGG GAC ATT CAA TAG CGT AGC; NK1R forward, AAC ACC TCG GAA CCC AAT CA; NK1R reverse, CAG CTG CCC AAA GGA CAA TT. Then, thermal cycling was performed as follows: initial denaturation at $95^{\circ} \mathrm{C}$ for 10 seconds followed by 40 cycles of $95^{\circ} \mathrm{C}$ for 5 seconds and $60^{\circ} \mathrm{C}$ to $65^{\circ} \mathrm{C}$ for 33 seconds. Expression levels of mRNA of the target gene were compared with the endogenous control $\beta$-actin using the $2^{-\Delta \Delta \mathrm{Ct}}$ method.

\section{Statistical analysis}

SPSS version 18.0 (SPSS Inc., Chicago, IL, USA) was used for all statistical analyses. Continuous variables were analyzed by using Student t-test, one-way analysis of variance, KruskalWallis test or Mann-Whitney test. Scheffe test was done as a post hoc test. Fisher exact test or Cochran's Q test were used for analysis of categorical variables. All results were considered statistically significant when $\mathrm{p}$-values were $<0.05$.

\section{RESULTS}

\section{General characteristics}

A total of 75 subjects were included in this study. Among them, 45 patients were categorized as the ERD group. The number of subjects included in the NERD group was 14 . The control group included 16 subjects who had neither endoscopic abnormalities nor reflux symptoms. Their demographic characteristics are summarized in Table 1. Mean age was older in the NERD group than ERD (54.3 vs 52.3, $\mathrm{p}=0.032$ ). The proportions

Table 1. Characteristics of the Participating Subjects

\begin{tabular}{|c|c|c|c|c|c|c|}
\hline \multirow{2}{*}{ Characteristic } & \multirow{2}{*}{$\begin{array}{l}\text { Control } \\
(\mathrm{n}=16)\end{array}$} & \multirow{2}{*}{$\begin{array}{l}\text { ERD } \\
(n=45)\end{array}$} & \multirow{2}{*}{$\begin{array}{l}\text { NERD } \\
(n=14)\end{array}$} & \multicolumn{3}{|c|}{$\mathrm{p}$-value } \\
\hline & & & & Control vs ERD & Control vs NERD & ERD vs NERD \\
\hline Age, yr & $52.7 \pm 13.8$ & $52.3 \pm 10.3$ & $54.3 \pm 11.6$ & 0.977 & 0.392 & $0.032^{*}$ \\
\hline Male & $52.1 \pm 14.4$ & $50.2 \pm 8.2$ & $54.1 \pm 10.9$ & \multicolumn{3}{|c|}{ 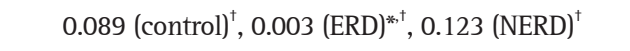 } \\
\hline Female & $53.6 \pm 12.9$ & $54.5 \pm 9.1$ & $54.5 \pm 11.4$ & & & \\
\hline Sex & & & & 0.114 & 0.224 & 0.392 \\
\hline Male & $7(43.8)$ & $23(51.1)$ & $7(50.0)$ & & & \\
\hline Female & $9(56.3)$ & $22(48.9)$ & $7(50.0)$ & & & \\
\hline Smoking & $4(25.0)$ & $11(24.4)$ & $5(35.7)$ & 0.394 & 0.341 & $0.012^{*}$ \\
\hline Alcohol & $9(56.3)$ & $23(51.1)$ & $9(64.3)$ & 0.134 & 0.243 & 0.249 \\
\hline BMI, $\mathrm{kg} / \mathrm{m}^{2}$ & $22.8 \pm 3.1$ & $24.6 \pm 3.1$ & $23.5 \pm 3.2$ & 0.345 & 0.244 & 0.459 \\
\hline Presence of reflux symptoms & 0 & & & - & - & $0.031^{*}$ \\
\hline Male & & $13(56.5)$ & 7 (100.0) & & & \\
\hline Female & & $19(86.4)$ & $7(100.0)$ & & & \\
\hline LA classification & - & & - & & $0.627^{\dagger}$ & \\
\hline A (male/female) & & 17 (73.9)/18 (81.8) & & & & \\
\hline B (male/female) & & $6(26.1) / 4(18.2)$ & & & & \\
\hline
\end{tabular}

Data are presented as mean \pm SD or number $(\%)$.

ERD, erosive reflux disease; NERD, nonerosive reflux disease; BMI, body mass index.

*Statistical significance; ${ }^{\dagger}$ Male vs female. 
of males and females were not significantly different among the groups. When comparing males and females, the mean age of females was older than that of males in all three groups. Especially in the ERD group, the mean age of females was signifi- cantly older than that of males ( 54.5 vs 50.2, $\mathrm{p}=0.003$ ). Among females, only three in the control group were premenopausal and the others were all menopausal. There were more smokers in the NERD group than in the ERD group (35.7\% vs $24.4 \%$,

Table 2. Reflux Symptoms in ERD and NERD

\begin{tabular}{|c|c|c|c|c|c|c|}
\hline \multirow{2}{*}{ Reflux symptoms } & \multicolumn{3}{|c|}{ ERD $(n=45)$} & \multicolumn{3}{|c|}{ NERD $(n=14)$} \\
\hline & Male $(n=23)$ & Female $(n=22)$ & p-value & Male $(\mathrm{n}=7)$ & Female $(\mathrm{n}=7)$ & p-value \\
\hline Heartburn & $13(56.5)$ & $17(77.3)$ & 0.207 & $7(100)$ & $7(100)$ & $>0.999$ \\
\hline Acid regurgitation & 13 (56.5) & $16(72.7)$ & 0.353 & $7(100)$ & $5(71.4)$ & 0.461 \\
\hline Chest pain & $13(56.5)$ & $15(68.2)$ & 0.378 & $6(85.7)$ & $4(57.1)$ & 0.559 \\
\hline Cough & $12(52.2)$ & $14(63.6)$ & 0.549 & $4(57.1)$ & $6(85.7)$ & 0.559 \\
\hline Globus sensation & $5(21.7)$ & $8(17.8)$ & 0.336 & $2(28.6)$ & $7(100)$ & $0.021^{*}$ \\
\hline Hoarseness & $9(39.1)$ & $11(50.0)$ & 0.554 & $5(71.4)$ & $4(57.1)$ & $>0.999$ \\
\hline Epigastric soreness & $10(22.2)$ & $8(17.8)$ & 0.763 & $6(85.7)$ & $5(71.4)$ & $>0.999$ \\
\hline Any one of above symptoms & $13(56.5)$ & 19 (86.4) & $0.047^{*}$ & $7(100)$ & $7(100)$ & $>0.999$ \\
\hline
\end{tabular}

Data are presented as number (\%).

ERD, erosive reflux disease; NERD, nonerosive reflux disease.

*Statistical significance.

Table 3. Comparing Reflux Symptoms and GERD Impact Scale between Males and Females in Symptomatic GERD Patients

\begin{tabular}{|c|c|c|c|}
\hline Reflux symptoms and GERD impact scale & Male $(n=20)$ & Female $(n=26)$ & p-value \\
\hline \multicolumn{4}{|l|}{ GERD symptoms } \\
\hline Chest pain & $1.8 \pm 0.4$ & $2.1 \pm 0.3$ & $0.003^{*}$ \\
\hline Heartburn & $1.7 \pm 0.5$ & $2.6 \pm 0.4$ & $0.001^{*}$ \\
\hline Acid regurgitation & $2.1 \pm 0.5$ & $2.7 \pm 0.3$ & $0.002^{*}$ \\
\hline Epigastric pain & $2.0 \pm 0.2$ & $2.5 \pm 0.2$ & $0.003^{*}$ \\
\hline Hoarseness & $2.0 \pm 0.3$ & $2.1 \pm 0.3$ & 0.801 \\
\hline Sleep disturbance & $1.6 \pm 0.2$ & $2.5 \pm 0.3$ & $0.002^{*}$ \\
\hline Eating problem & $1.6 \pm 0.3$ & $2.1 \pm 0.3$ & $0.003^{*}$ \\
\hline Limiting of productive daily activities & $1.4 \pm 0.4$ & $2.4 \pm 0.4$ & $0.001^{*}$ \\
\hline Use of additional un-prescribed medication & $1.8 \pm 0.4$ & $2.2 \pm 0.3$ & $0.002^{*}$ \\
\hline
\end{tabular}

Data are presented as mean \pm SD.

GERD, gastroesophageal reflux disease.

*Statistical significance.

Table 4. Comparing WHOQOL-BREF Score between Groups

\begin{tabular}{|c|c|c|c|c|c|c|}
\hline \multirow{2}{*}{ WHOQOL-BREF score } & \multirow{2}{*}{$\begin{array}{c}\text { Control } \\
(n=16)\end{array}$} & \multirow{2}{*}{$\begin{array}{c}\text { ERD } \\
(n=45)\end{array}$} & \multirow{2}{*}{$\begin{array}{l}\text { NERD } \\
(\mathrm{n}=14)\end{array}$} & \multicolumn{3}{|c|}{ p-value } \\
\hline & & & & Control vs ERD & Control vs NERD & ERD vs NERD \\
\hline Total & $63.8 \pm 2.4$ & $57.8 \pm 2.4$ & $54.9 \pm 2.3$ & $0.014^{*}$ & $0.002^{*}$ & 0.630 \\
\hline Overall quality of life and general health & $6.9 \pm 0.3$ & $6.4 \pm 0.2$ & $5.6 \pm 0.2$ & $0.008^{*}$ & $0.001^{*}$ & 0.095 \\
\hline Physical domain & $14.0 \pm 0.5$ & $13.6 \pm 0.3$ & $12.0 \pm 0.6$ & 0.928 & $0.004^{*}$ & 0.051 \\
\hline Psychological domain & $14.2 \pm 0.1$ & $13.1 \pm 0.5$ & $12.1 \pm 0.4$ & $0.015^{*}$ & $0.002^{*}$ & 0.334 \\
\hline Social domain & $14.2 \pm 0.5$ & $13.0 \pm 0.6$ & $12.5 \pm 0.6$ & 0.224 & $0.010^{*}$ & 0.929 \\
\hline Environmental domain & $14.4 \pm 0.7$ & $12.5 \pm 0.6$ & $13.8 \pm 0.2$ & $0.018^{*}$ & 0.072 & 0.560 \\
\hline
\end{tabular}

Data are presented as mean \pm SD.

WHOQOL-BREF, World Health Organization quality of life scale abbreviated version; ERD, erosive reflux disease; NERD, nonerosive reflux disease. *Statistical significance. 
$\mathrm{p}=0.012)$.

\section{Reflux symptoms, GIS and QOL}

As Table 2 shows, the proportion of patients with reflux symptoms was significantly higher in the NERD group than the ERD group (100.0\% vs 77.8\%, $\mathrm{p}=0.02$ ). Especially, extra-esophageal symptoms, such as globus sensation and epigastric soreness were more prevalent in the NERD group than in the ERD group with statistical significance $(78.6 \%$ vs $46.7 \%, \mathrm{p}=0.01 ; 71.4 \%$ vs $44.4 \%, p=0.02$; respectively). In the analysis of each group comparing males and females, the prevalence of each specific symptom was similar to each other in the ERD group. However, the proportion of symptomatic ERD patients was significantly higher in the females than in males (86.4\% vs $56.5 \%, p=0.047)$. In the NERD group, globus sensation was more prevalent in females than in males with statistical significance $(100.0 \%$ vs 28.6\%, $\mathrm{p}=0.021$ ). Other than globus sensation, the prevalences of other symptoms were not significantly different between males and females.

When comparing GIS between symptomatic males and females, females scored significantly higher than males, concerning chest pain, heartburn, acid regurgitation and epigastric pain $(1.8 \pm 0.4$ vs $2.1 \pm 0.3, p=0.003 ; 1.7 \pm 0.5$ vs $2.6 \pm 0.4, p=0.001$; $2.1 \pm 0.5$ vs $2.7 \pm 0.3, p=0.002 ; 2.0 \pm 0.2$ vs $2.5 \pm 0.2, p=0.003$; respectively). Also every variable in the impact of symptoms, including sleep disturbance, eating problem, limiting of productive daily activities, and use of additional un-prescribed medication, scored significantly higher in the females than in males $(1.6 \pm 0.2$ vs $2.5 \pm 0.3, \mathrm{p}=0.002 ; 1.6 \pm 0.3$ vs $2.1 \pm 0.3, \mathrm{p}=0.003 ; 1.4 \pm 0.4$ vs $2.4 \pm 0.4, \mathrm{p}=0.001 ; 1.8 \pm 0.4$ vs $2.2 \pm 0.3, \mathrm{p}=0.002$; respectively) (Table 3).

In terms of QOL with WHOQOL-BREF questionnaires, the differences of the scores in many variables between ERD/NERD and control groups were significant, showing more impaired QOL in the ERD/NERD patients than in the control group (Table 4). When comparing males and females, the scores of total, overall QOL and general health, and psychological domain in females were significantly lower than in males $(54.9 \pm 2.3$ vs
$44.7 \pm 1.9, \mathrm{p}=0.012 ; 5.6 \pm 0.2$ vs $4.9 \pm 0.6, \mathrm{p}=0.009 ; 12.1 \pm 0.4$ vs $11.2 \pm 0.3, p=0.013$; respectively) (Table 5).

\section{Comparison of tight junction protein-related gene mRNA expression levels}

We analyzed whether sex, endoscopic findings and reflux symptoms were associated with OCLN, CLDN1, CLDN4, ZO-1 and NK1R mRNA expression levels (Fig. 1). As Fig. 1A (b) shows, ERD males showed significantly lower OCLN mRNA expression levels than control males $(1.57 \pm 0.32$ vs $1.07 \pm 0.71$, $\mathrm{p}=0.032$ ). In terms of CLND1 (Fig. 1B), ERD group showed significant up-regulation compared to the control group, both in males $(1.49 \pm 0.52$ vs $0.23 \pm 0.49, p=0.029)$ and females $(1.48 \pm 0.43$ vs $0.42 \pm 0.26, p=0.034)$. The levels of CLDN4 were significantly higher only in the male ERD group than in the male control group $(1.67 \pm 9.27$ vs $0.98 \pm 0.18, p=0.021)$ (Fig. $1 \mathrm{C}$ [a and b]). The levels of Z0-1 mRNA expression were not significantly different among the groups (Fig. 1D). In all groups, the presence of reflux symptoms was not significantly associated with tight junction protein expression levels (Fig. 1A [c], B [c], C [c], D [c]).

Lastly, NK1R which is one of the neuro-inflammation related neuropeptide, was significantly up-regulated in the male ERD group than in the male control group $(0.27 \pm 0.21$ vs $1.71 \pm 0.27$, $\mathrm{p}=0.001$ ) (Fig.1E [b]). Similar to other molecules, reflux symptoms did not significantly affect the levels of NK1R mRNA expression (Fig. 1E [c]).

\section{DISCUSSION}

We demonstrated that reflux symptoms affected more and QOL was also more impaired in the female GERD patients than in the male GERD patients. The levels of OCLN mRNA expression were significantly lower in the ERD males, whereas those of CLDN1, CLDN4, and NK1R were significantly higher in the ERD males. Presence of reflux symptoms did not exhibit a significant relationship with tight junction protein changes.

As mentioned above, in female ERD patients, they suffered more GERD symptoms and their QOL was more impaired (Table 2). In-

Table 5. Comparing WHOQOL-BREF Score between Males and Females

\begin{tabular}{|c|c|c|c|}
\hline \multirow{2}{*}{ WHOQOL-BREF score } & \multicolumn{2}{|c|}{ Reflux symptoms (+) } & \multirow{2}{*}{ p-value } \\
\hline & Male $(n=20)$ & Female $(n=26)$ & \\
\hline Total & $54.9 \pm 2.3$ & $44.7 \pm 1.9$ & $0.012^{*}$ \\
\hline Overall quality of life and general health & $5.6 \pm 0.2$ & $4.9 \pm 0.6$ & $0.009^{*}$ \\
\hline Physical domain & $12.0 \pm 0.6$ & $11.8 \pm 0.8$ & 0.928 \\
\hline Psychological domain & $12.1 \pm 0.4$ & $11.2 \pm 0.3$ & $0.013^{*}$ \\
\hline Social domain & $12.5 \pm 0.6$ & $11.9 \pm 0.4$ & 0.224 \\
\hline Environmental domain & $12.8 \pm 0.2$ & $12.3 \pm 0.6$ & 0.110 \\
\hline
\end{tabular}

Data are presented as mean \pm SD.

WHOQOL-BREF, World Health Organization quality of life abbreviated version.

*Statistical significance. 
A OCLN
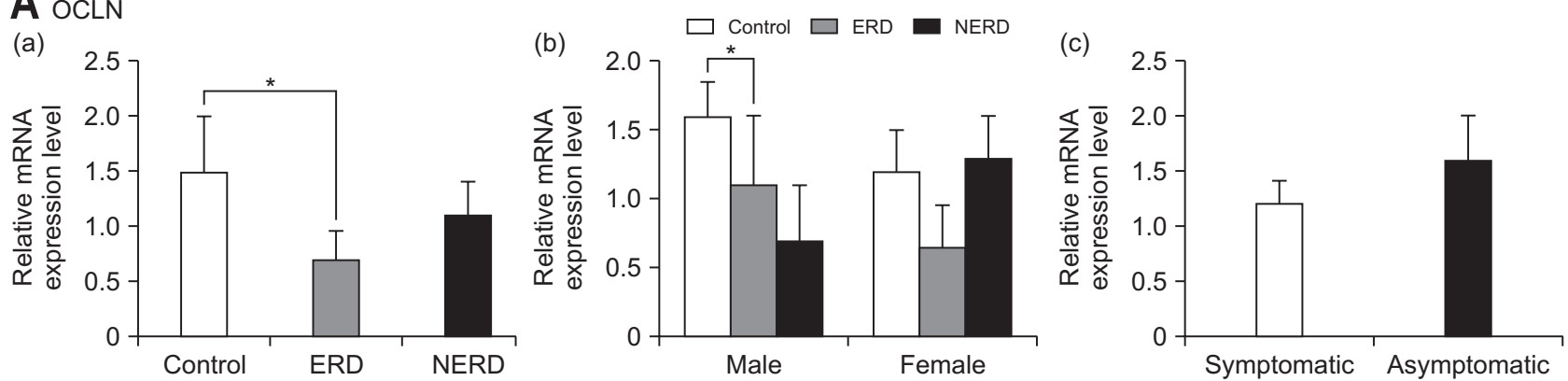

B CLDN1
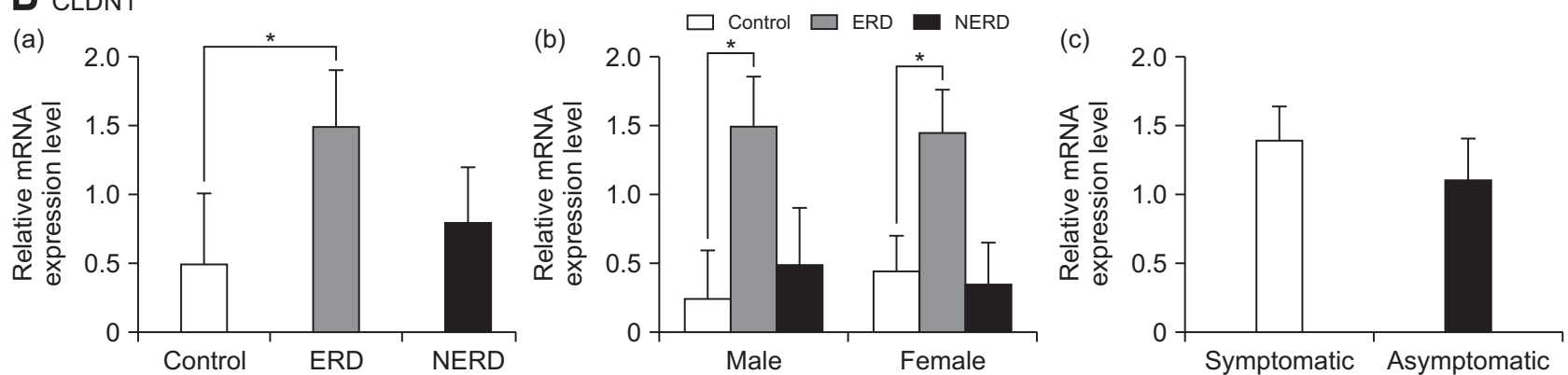

C CLDN4
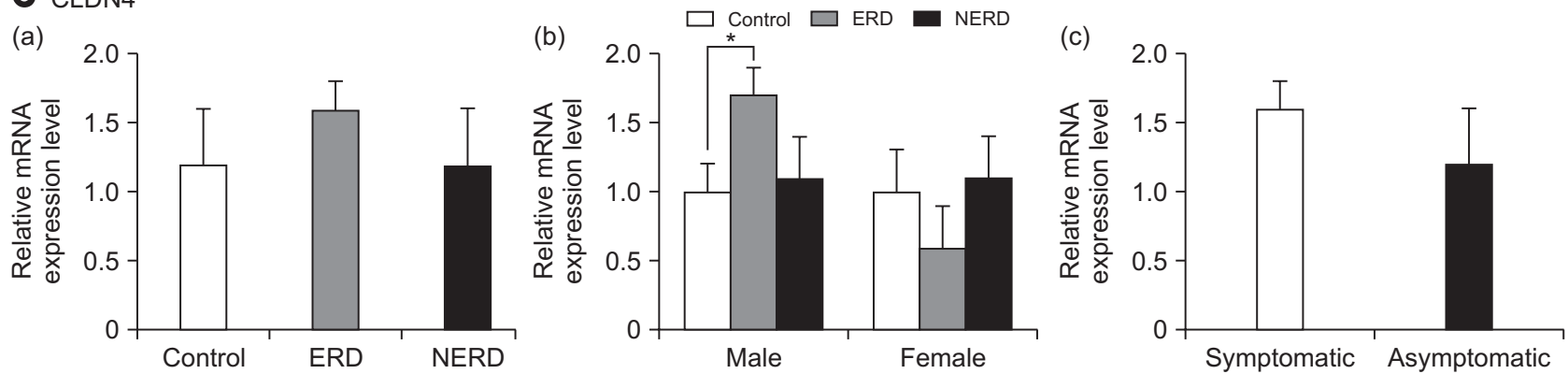

D zo-1
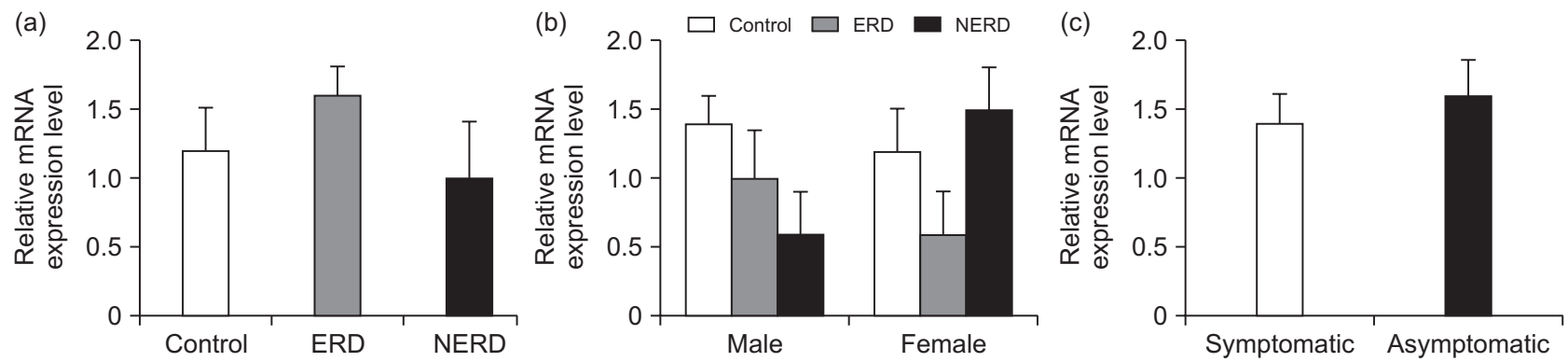

$\mathbf{E}_{\mathrm{NK} 1 \mathrm{R}}$
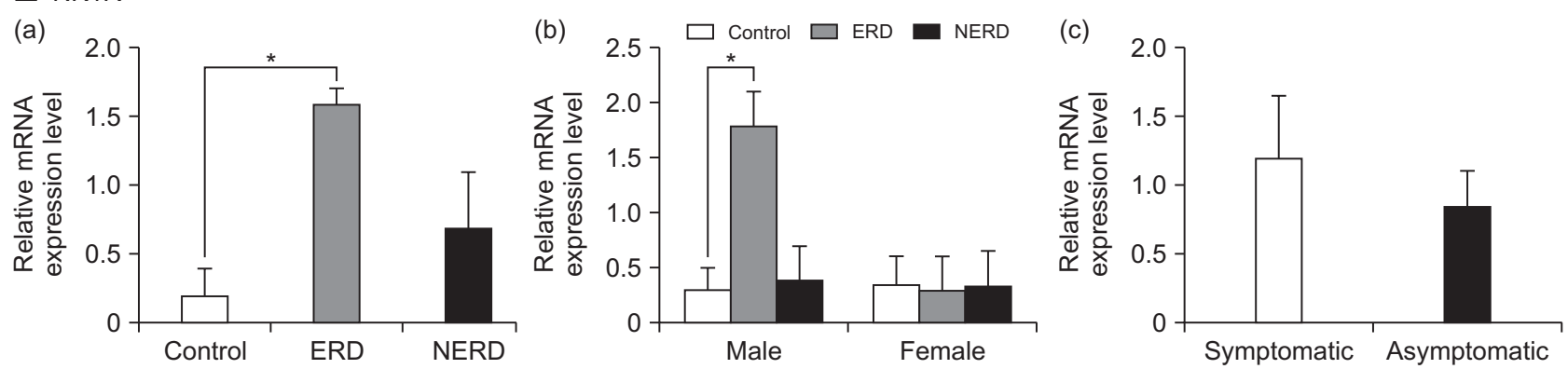

Fig. 1. Comparison of OCLN (A), CLDN1 (B), CLDN4 (C), ZO-1 (D) and NK1R (E) mRNA expression levels. Relative mRNA expression levels of each protein are described as below. (a) Comparison among the control, erosive reflux disease (ERD), and nonerosive reflux disease (NERD) groups. (b) Comparison between males and females. (c) Comparison between symptomatic and asymptomatic patients.

OCLN, occludin; CLDN1, claudin 1; CLDN4, claudin 4; ZO-1, zonal occludens 1, NK1R, neurokinin 1 receptor. *p $<0.05$ vs control group. 
terestingly, there were more asymptomatic patients in the male ERD group. Females seem to perceive more pain than males and also be affected more in daily lives. Thus, more vigorous symptomatic intervention strategies would be necessary for female GERD patients.

In the pathogenesis of GERD, disruption of the esophageal barrier function has been considered to be important as an early parameter of resistance against intraluminal reflux substance. The role of gastric acid in disrupting the esophageal barrier function has been shown in several animal studies. ${ }^{19-21,34}$ In concordance with these studies, our study suggested that endoscopic erosive esophagitis are related with altered tight junction protein expression levels. On the other hand, reflux symptoms were not related to these changes. Thus, tight junction disruption and inflammation itself seem to be not enough to develop reflux symptoms. To cause the reflux symptoms, something more than these molecular changes, such as brain gut axis or nociceptive perception process, or visceral hypersensitivity, might be necessary. $^{35-37}$

So far, several epidemiologic studies have demonstrated a profound male predominance in the prevalence of GERD, including ERD, BE and EAC, irrespective of country, ethnicity and decade. ${ }^{36-38}$ We speculated that this male predominance would be caused by the differences in the esophageal epithelial barrier functions. That is, estrogen would play a protective role against the development of GERD by promoting esophageal epithelial barrier function. However, we could not find any significant relationship between sex and tight junction protein mRNA expression levels. We acknowledge that it is necessary to be careful when interpreting the data because it might be biased during the patient selection process in this study. Only three of female control group patient were premenopausal and there were no premenopausal females either in ERD or NERD group. According to several animal studies, ${ }^{36-38}$ sex differences in nociceptive behaviors have been observed with responses in females being greater than males, depending on the reproductive cycle. Therefore, it would be more appropriate for comparing the effect of sex on the tight junction proteins if there were more patients under 40 and premenopausal.

According to previous studies, mRNA expression levels of OCLN, CLDN1, CLDN2, CLDN4 and ZO-1 have been upregulated in ERD patient. ${ }^{19,20,26}$ However, in this study, OCLN was down-regulated on the contrary to other molecules. The discrepancies could be explained by the polarity of tight junctions, which is one of the distinctive characteristics of tight junction proteins. Usually they present on the apical end of the lateral membrane surface in columnar epithelial cells to form a barrier against paracellular transport and maintain apicobasal cell polarity through their fence function. ${ }^{24}$ When considering the structural traits, there would be a molecular "redistribution" rather than a change in absolute expression levels. Oshima and Miwa $^{39}$ provided further support for this assumption, report- ing that esophageal acid exposure caused a "delocalization" of CLDN4 from superficial layer of the mucosa. Furthermore, it is thought that only the detergent non-soluble fraction would have an actual function, thus the total amount would not correlate with the functional status. Therefore, specific measurement of those detergent non-soluble fraction would be requisite for the evaluation of tight junction proteins substantial status. For example, Z0-1 is a cytosolic tight junction protein, which mainly interacts with other transmembrane tight junction proteins and cytoskeletal molecules. Thus, the total amount of ZO-1 might not be able to reflect the exact functional status of this protein. Thus, localization of this protein or specific measurement of detergent non-soluble fraction would be necessary for more elaborate characterization.

Molecular changes of the esophageal mucosa could be a valuable tool aiding the diagnosis of GERD. Currently, GERD is diagnosed with either objective endoscopic tissue damage or subjective symptoms possibly related to reflux. There is no single gold standard diagnostic test, so far. However, none of any possible reflux symptoms are specific for GERD, resulting in high possibilities for diagnostic errors. Considering those diagnostic difficulties, identification of molecular biomarkers for GERD would be a valuable clinical tool in identifying and managing patients with refractory GERD. From this background, biomarkers of mucosal injury have been studied and tight junction proteins are one of those. Promisingly, animal and in vitro models of GERD have manifested significant changes of tight junction proteins and these changes also have been observed in several human studies. Unfortunately, their relationship with NERD is not solidly established yet. This might be resulted from unavoidable selection bias, due to the limitation of current diagnostic standard and heterogeneity of the NERD patient group. Further studies are warranted in this respect.

There are several limitations to be acknowledged in this study. First of all, we defined NERD group with using PPIresponse and did not apply $\mathrm{pH}$ monitoring study. Indeed, previous studies have underlined the limitation of PPI test. ${ }^{40,41}$ Not only "true" GERD patients but also PPI responsive visceral hypersensitivity patients might have been included in this study, whereas patients with non-acid or weakly acid reflux would not be included properly. Twenty-four hour $\mathrm{pH}$ monitoring could not be performed for most of the enrolled subjects because of its cumbersomeness and high false-negative rates. Moreover, there must be some placebo effects in some patients. In addition, the number of subjects who were enrolled in this study was relatively small because it was not easy to get the consent from the patients due to the invasiveness of esophageal mucosal biopsy. Also, small amount of biopsy specimen was not enough for the Western blot and histopathologic studies and we could not evaluate the relationship between tight junction protein mRNA expression levels and histopathological changes, such as dilated intercellular spaces, basal cell hyperplasia, and elongation of 
papillae.

In conclusion, we demonstrated that female ERD/NERD patients were affected more by GERD and male ERD patients showed significant changes of tight junction protein mRNA expression levels.

\section{CONFLICTS OF INTEREST}

No potential conflict of interest relevant to this article was reported.

\section{ACKNOWLEDGEMENTS}

This research was supported by Support Program for Women in Science, Engineering and Technology through the National Research Foundation of Korea (NRF) funded by the Ministry of Science, ICT and Future Planning (grant number: 2016H1C3A1903202).

\section{REFERENCES}

1. Boeckxstaens G, El-Serag HB, Smout AJ, Kahrilas PJ. Symptomatic reflux disease: the present, the past and the future. Gut 2014;63:1185-1193.

2. El-Serag HB, Sweet S, Winchester CC, Dent J. Update on the epidemiology of gastro-oesophageal reflux disease: a systematic review. Gut 2014;63:871-880.

3. Jung HK. Epidemiology of gastroesophageal reflux disease in Asia: a systematic review. J Neurogastroenterol Motil 2011;17:1427.

4. Chiocca JC, Olmos JA, Salis GB, et al. Prevalence, clinical spectrum and atypical symptoms of gastro-oesophageal reflux in $\mathrm{Ar}-$ gentina: a nationwide population-based study. Aliment Pharmacol Ther 2005;22:331-342.

5. Cho YS, Choi MG, Jeong JJ, et al. Prevalence and clinical spectrum of gastroesophageal reflux: a population-based study in Asan-si, Korea. Am J Gastroenterol 2005;100:747-753.

6. Chen M, Xiong L, Chen H, Xu A, He L, Hu P. Prevalence, risk factors and impact of gastroesophageal reflux disease symptoms: a population-based study in South China. Scand J Gastroenterol 2005;40:759-767.

7. Mishima I, Adachi K, Arima N, et al. Prevalence of endoscopically negative and positive gastroesophageal reflux disease in the Japanese. Scand J Gastroenterol 2005;40:1005-1009.

8. Seo GS, Jeon BJ, Chung JS, et al. The prevalence of erosive esophagitis is not significantly increased in a healthy Korean population: could it be explained? A multi-center prospective study. J Neurogastroenterol Motil 2013;19:70-77.

9. Shim KN, Hong SJ, Sung JK, et al. Clinical spectrum of reflux esophagitis among 25,536 Koreans who underwent a health check-up: a nationwide multicenter prospective, endoscopy-based study. J Clin Gastroenterol 2009;43:632-638.
10. Lee JH, Kim N, Chung IK, et al. Clinical significance of minimal change lesions of the esophagus in a healthy Korean population: a nationwide multi-center prospective study. J Gastroenterol Hepatol 2008;23(7 Pt 1):1153-1157.

11. Peng S, Cui Y, Xiao YL, et al. Prevalence of erosive esophagitis and Barrett's esophagus in the adult Chinese population. Endoscopy 2009;41:1011-1017.

12. Ford AC, Forman D, Reynolds PD, Cooper BT, Moayyedi P. Ethnicity, gender, and socioeconomic status as risk factors for esophagitis and Barrett's esophagus. Am J Epidemiol 2005;162:454-460.

13. Park JJ, Kim JW, Kim HJ, et al. The prevalence of and risk factors for Barrett's esophagus in a Korean population: a nationwide multicenter prospective study. J Clin Gastroenterol 2009;43:907-914.

14. Derakhshan MH, Liptrot S, Paul J, Brown IL, Morrison D, McColl KE. Oesophageal and gastric intestinal-type adenocarcinomas show the same male predominance due to a 17 year delayed development in females. Gut 2009;58:16-23.

15. Kim YS, Kim N, Kim GH. Sex and gender differences in gastroesophageal reflux disease. J Neurogastroenterol Motil 2016;22:575-588.

16. Annandale E, Hammarström A. Constructing the 'gender-specific body': a critical discourse analysis of publications in the field of gender-specific medicine. Health (London) 2011;15:571-587.

17. Kilminster S, Downes J, Gough B, Murdoch-Eaton D, Roberts T. Women in medicine: is there a problem? A literature review of the changing gender composition, structures and occupational cultures in medicine. Med Educ 2007;41:39-49.

18. Oguro M, Koike M, Ueno T, et al. Dissociation and dispersion of claudin-3 from the tight junction could be one of the most sensitive indicators of reflux esophagitis in a rat model of the disease. J Gastroenterol 2011;46:629-638.

19. Oshima T, Koseki J, Chen X, Matsumoto T, Miwa H. Acid modulates the squamous epithelial barrier function by modulating the localization of claudins in the superficial layers. Lab Invest 2012;92:22-31.

20. Mönkemüller K, Wex T, Kuester D, et al. Role of tight junction proteins in gastroesophageal reflux disease. BMC Gastroenterol 2012;12:128

21. Tan JC, Cui WX, Heng D, Lin L. ERK1/2 participates in regulating the expression and distribution of tight junction proteins in the process of reflux esophagitis. J Dig Dis 2014;15:409-418.

22. Weijenborg PW, Smout AJ, Verseijden C, et al. Hypersensitivity to acid is associated with impaired esophageal mucosal integrity in patients with gastroesophageal reflux disease with and without esophagitis. Am J Physiol Gastrointest Liver Physiol 2014;307:G323-G329.

23. Tsukita S, Furuse M. Pores in the wall: claudins constitute tight junction strands containing aqueous pores. J Cell Biol 2000;149:13-16.

24. Tsukita S, Furuse M. The structure and function of claudins, cell adhesion molecules at tight junctions. Ann N Y Acad Sci 2000;915:129-135. 
25. Honda J, Iijima K, Asanuma K, et al. Estrogen enhances esophageal barrier function by potentiating occludin expression. Dig Dis Sci 2016;61:1028-1038.

26. Masaka T, Iijima K, Endo H, et al. Gender differences in oesophageal mucosal injury in a reflux oesophagitis model of rats. Gut 2013;62:6-14.

27. Kim JJ, Kim N, Choi YJ, Kim JS, Jung HC. Increased TRPV1 and PAR2 mRNA expression levels are associated only with the esophageal reflux symptoms, but not with the extraesophageal reflux symptoms. Medicine (Baltimore) 2016;95:e4387.

28. Jo SY, Kim N, Lim JH, et al. Comparison of gastroesophageal reflux disease symptoms and proton pump inhibitor response using gastroesophageal reflux disease impact scale questionnaire. J Neurogastroenterol Motil 2013;19:61-69.

29. Kim JY, Kim N, Seo PJ, et al. Association of sleep dysfunction and emotional status with gastroesophageal reflux disease in Korea. J Neurogastroenterol Motil 2013;19:344-354.

30. Kim SE, Kim N, Oh S, et al. Predictive factors of response to proton pump inhibitors in Korean patients with gastroesophageal reflux disease. J Neurogastroenterol Motil 2015;21:69-77.

31. Jones R, Coyne K, Wiklund I. The gastro-oesophageal reflux disease impact scale: a patient management tool for primary care. Aliment Pharmacol Ther 2007;25:1451-1459.

32. Development of the World Health Organization WHOQOL-BREF quality of life assessment. The WHOQOL Group. Psychol Med 1998;28:551-558.

33. Skevington SM, Lotfy M, O'Connell KA; WHOQOL Group. The World Health Organization's WHOQOL-BREF quality of life as- sessment: psychometric properties and results of the international field trial: a report from the WHOQOL group. Qual Life Res 2004;13:299-310.

34. Orlando RC, Bryson JC, Powell DW. Mechanisms of H+ injury in rabbit esophageal epithelium. Am J Physiol 1984;246(6 Pt 1):G718-G724.

35. Meerveld BG, Johnson AC. Mechanisms of stress-induced visceral pain. J Neurogastroenterol Motil 2018;24:7-18.

36. Cook MB, Wild CP, Forman D. A systematic review and metaanalysis of the sex ratio for Barrett's esophagus, erosive reflux disease, and nonerosive reflux disease. Am J Epidemiol 2005;162:1050-1061.

37. Kayser V, Berkley KJ, Keita H, Gautron M, Guilbaud G. Estrous and sex variations in vocalization thresholds to hindpaw and tail pressure stimulation in the rat. Brain Res 1996;742:352-354.

38. Chaloner A, Greenwood-Van Meerveld B. Sexually dimorphic effects of unpredictable early life adversity on visceral pain behavior in a rodent model. J Pain 2013;14:270-280.

39. Oshima T, Miwa H. Gastrointestinal mucosal barrier function and diseases. J Gastroenterol 2016;51:768-778.

40. Numans ME, Lau J, de Wit NJ, Bonis PA. Short-term treatment with proton-pump inhibitors as a test for gastroesophageal reflux disease: a meta-analysis of diagnostic test characteristics. Ann Intern Med 2004;140:518-527.

41. Dent J, Vakil N, Jones R, et al. Accuracy of the diagnosis of GORD by questionnaire, physicians and a trial of proton pump inhibitor treatment: the Diamond Study. Gut 2010;59:714-721. 